\title{
Laboreal
}

Volume $17 \mathrm{~N}^{\circ} 1 \mid 2021$

Trabalhar hoje: mudanças, permanências, estratégias, reinvenções

\section{Psicología e historia}

\section{Psicologia e história}

Psychologie et histoire

Psychology and history

\section{Lucien Febvre}

Traductor: María Noel Close (psicmariaclose@gmail.com)

\section{OpenEdition Journals}

\section{Edición electrónica}

URL: https://journals.openedition.org/laboreal/18018

ISSN: 1646-5237

Editor

Universidade do Porto

Referencia electrónica

Lucien Febvre, «Psicología e historia», Laboreal [En línea], Volume 17 Nº1 | 2021, Publicado el 18 junio 2021, consultado el 20 junio 2021. URL: http://journals.openedition.org/laboreal/18018

Este documento fue generado automáticamente el 20 junio 2021.

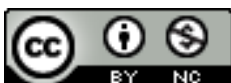

Laboreal está licenciado com uma Licença Creative Commons - Atribuição-NãoComercial 4.0 Internacional. 


\title{
Psicología e historia
}

\author{
Psicologia e história \\ Psychologie et histoire \\ Psychology and history
}

\section{Lucien Febvre}

Tradución : María Noel Close (psicmariaclose@gmail.com)

\section{REFERENCIA}

Texto original : Febvre, L. (1938). Psychologie et histoire. In H. Henri Wallon (Dir.), La vie mentale. L'Encyclopédie Française, Tome VIII (pp. 8'12-3 - 8'12-7). Paris : Larousse.

1 La capacidad para descubrir correlaciones : en muchos casos, es una de las definiciones más satisfactorias del talento científico: piense en el gran médico que, agrupando signos y síntomas dispersos, realmente "inventa" y "crea" una nueva enfermedad. La capacidad de negociar acuerdos e intercambios entre disciplinas afines: para una ciencia en proceso de expansión, ésta es una definición no menos correcta de progreso. Esta verdad (que proviene de la experiencia) se traduce a veces de otra manera: "los grandes descubrimientos se hacen siempre en las mismas fronteras de las ciencias".

2 Psicología, historia : una alianza y sus propósitos - En primer lugar, la psicología, conocimiento científico de la función mental, debe necesariamente estrechar sus vínculos con el conocimiento científico de la función social, la sociología en proceso de elaboración : que no menos necesariamente debe establecer relaciones persistentes con ciertas disciplinas que mantenemos confundidas bajo el nombre tradicional de historia - esto es lo que no requiere largas explicaciones. Que en la actualidad estas relaciones sólo puedan ser bastante falaces es lo que cabría esperar. La psicología se desprende apenas de las controversias filosóficas para asentarse en el terreno sólido de la investigación experimental. La sociología no ha sido nombrada en la humanidad hasta hace apenas un siglo, y no ha contenido sustancia hasta un periodo de tiempo mucho más corto. En cuanto a las disciplinas que desde hace un siglo están separadas del 
confuso magma de la historia, ni siquiera tienen estatuto. Con mayor razón, en esta Enciclopedia, que no pretende ser un mero estereotipo de los resultados adquiridos, no deben descuidarse los aspectos cambiantes de la vida de las ciencias humanas.

3 Entre psicólogos, sociólogos e historiadores, ¿cuáles serían, a primera vista, las apuestas en un debate de competencias y atribuciones? Evidentemente, el conocimiento del individuo. "La psicología, decía Baldwin, se ocupa del individuo, la sociología del grupo". En cuanto a la historia, imagino que si Baldwin la hubiera definido, habría encerrado en ella al individuo y al grupo dentro del mismo campo y habría profesado que, armado con los resultados adquiridos por la psicología y la sociología, se esforzaría por definir, en el marco del pasado, sus relaciones recíprocas. Excelentes nociones para los estudiantes: son claras, sencillas, proporcionan claves fáciles de usar. La desgracia es que, cuando se utilizan, siempre dejan la segunda puerta cerrada. En lugar de disertar en abstracto y diseñar sobre el papel lo que se deja escribir con límites bien definidos, enfrentémonos a la realidad y apliquemos el método correcto : complicar lo que parece demasiado simple.

\section{Desde el punto de vista de la historia}

4 ¿Cuál es el objeto de estudio del historiador? La opinión común responde : por un lado, los movimientos confusos de masas anónimas de hombres, indistintos, indiscernibles, dedicados de alguna manera a las ocupaciones menos consideradas y valoradas de la historia ; por otro lado, emergiendo de esta grisura, y destacando con claridad de la penumbra, la acción dirigente de un cierto número de individuos calificados como "personajes históricos".

5 Las masas son poco conocidas. Hay pocos medios para conocerlos. Épocas enteras no nos han dejado ningún testimonio directo y detallado sobre ellas. Aristocrática en sus orígenes, la historia no tuvo ojos durante siglos y muy a menudo sólo los tiene para los reyes y príncipes, los líderes de los pueblos y los ejércitos ; los hombres "que hacen la historia", Menschen die Geschischte machen - es el título de una voluminosa colección de biografías históricas recientemente publicada en Alemania. Así, las relaciones entre la psicología y la historia se establecen, según la opinión común, de forma muy sencilla. ¿Las masas anónimas ? Serán la justificación de una psicología colectiva fundada en el estudio de las masas actualmente accesibles, que extendería sin esfuerzo (supuestamente al menos) sus conclusiones a las masas desaparecidas; a las masas de antaño, a las masas históricas. En cuanto a los individuos diferenciados, los personajes históricos pertenecen naturalmente a la psicología individual. Los documentos que les pertenecen, muchos de los cuales llevan una interpretación psicológica de su actividad y carácter, serán fáciles de entender para los psicólogos. Engrandecerán el tesoro de sus observaciones. A la inversa, las conclusiones que éstos puedan extraer del estado de los casos humanos que tienen bajo sus ojos, permitirán a los historiadores interpretar y comprender mejor la conducta y la acción de los dirigentes de las sociedades de antaño, auténticos artífices de la historia humana.

6 Y así, aquí estamos de nuevo y siempre frente al binomio individuo-sociedad. Pero sigamos analizando el problema.

7 Lo que es el individuo en la historia. ¿Qué son esos individuos prestigiosos, esas personalidades emergentes, esas figuras históricas? Respondimos hace poco, durante la tercera Semana Internacional de la Síntesis en la que se habló de la individualidad: 
son los autores responsables de una gran obra histórica. Pero ¿qué es una gran obra histórica? Conjunto de hechos recogidos, agrupados, organizados por los historiadores de manera que constituyan uno de los anillos de una de esas grandes cadenas de hechos homogéneos y distintos, políticos, económicos, religiosos, etc., con los que, los historiadores, construimos la red más o menos tupida del pasado histórico de la humanidad. Es la historia la que forja estas cadenas y las refuerza incesantemente en su necesidad de organizar el pasado, de introducir claridad y orden en el conjunto en perpetuo movimiento, en el deslumbramiento y el centelleo de los hechos que sin ley aparente chocan, se mezclan y se ordenan recíprocamente en torno a cada hombre, en cada momento de su vida -y, por tanto, de la vida de las sociedades en las que participa.

8 Lo que es la obra histórica - Grandes secuencias, grandes desarrollos: ¿por qué grandes? Porque es necesario distinguir entre las obras humanas aquellas que sólo interesan a un pequeño y determinado grupo de hombres y otras que, más allá de los límites de estos pequeños grupos, tienden a unirlos o al menos a orientarlos en la misma dirección. Como las religiones, en la medida en que no son religiones cerradas de grupos, prohibidas a todos los no-participantes de ellos. Como los grandes sistemas de ideas y doctrinas que se extienden más allá de las fronteras e interconectan a los hombres de todos los grupos. Igualmente, las obras políticas: organizaciones y revoluciones, conquistas y expansiones con toda la procesión de adhesiones por un lado y resistencias por el otro. ¿Obras históricas? Sí, en la medida en que no sólo son fruto de la violencia, sino que se benefician de la colaboración de la duración y de la adhesión de los hombres a los que, habiéndoseles impuesto inicialmente, acaban aceptándolos, incluso adoptándolos y luego difundiéndolos. Sí, en la medida en que no sean llevadas a cabo por unos pocos hombres únicamente para el uso y beneficio de unos pocos grupos, sino que puedan expresar un esfuerzo conjunto para organizar la vida de las masas humanas. Sí, en la medida en que lo que inicialmente era obra de particularismo y, si se quiere, de egoísmo, se transforma en una obra de civilización. ¿No es la civilización, como ha demostrado Marcel Mauss, un conjunto de hechos que no se limitan a una sociedad determinada, sino que son susceptibles de migraciones y de implantación en dominios a veces muy distantes y diferentes de su dominio de origen? ¿Hechos viajeros, hechos transportables, que saliendo de un grupo son prestados, adoptados, utilizados por otros grupos?

9 Cómo colabora el individuo con el grupo - Así, la obra histórica es : aquella que, más allá de lo local y nacional, apunta a lo humano. Lo que se afirma como susceptible de irradiación humana y de expansión pacífica. ¿Y entonces el personaje histórico ? Responde a una exigencia elemental de la creencia común. Todo reloj presupone un relojero. Toda obra histórica postula un autor. Debe entrar en juego la categoría fundamental de la creación : padre-hijo.

10 El padre de la obra histórica es el personaje histórico. Si se prefiere, invirtiendo los términos, el personaje histórico es el hombre al que la creencia común atribuye la paternidad de una obra histórica; simplificación necesaria y mnemotecnia conveniente. Pero ¿es cierto lo que acabamos de decir? Si el autor, y no el "supuesto" autor de una obra de organización colectiva con repercusión duradera, es decir, el autor "garantizado" de una gran obra científica, literaria, filosófica o religiosa que parece surgir realmente de su cerebro (Darwin, Shakespeare, Marx, Calvin), ese autor no sabría conferir eficacia a esa obra sin la colaboración, ¿sin la participación del grupo que la adoptó? ¿Es normal, el drama del hombre que lanza una idea y que vuelve 
totalmente deformada, transformada y desnaturalizada por el entorno? Si es inconfundible la aventura de Martín Luther, auténtico padre del luteranismo, pero confesando cien veces su perturbación, su desaliento cuando tuvo que constatar cómo las masas, desde el inicio, deformaban sus ideas, apropiándoselas y haciéndolas sufrir el destino que conocen todos los grandes creadores de ideas o de sentimientos: esta deformación, esta transformación, a veces inversión total de sus ideas, pero que tienen que soportar a pesar de todo ante la historia una paternidad que no es más que ilusoria y que a menudo les pesa, que querrían repudiar, que tienen que aceptar?

El grupo dentro del individuo : el lenguaje y la técnica - Más allá de ser un personaje histórico, ¿dónde está el ser humano que puede considerarse una potencia autónoma, independiente y aislada, una especie de creación original y espontánea, mientras que la persona humana en su conjunto sufre tan fuertemente las influencias, algunas procedentes del fondo del tiempo, otras ejercidas de la manera más inmediata por el entorno actual y transmitidas inmediatamente por esos dos agentes por excelencia, de penetración de la sociedad en el individuo : el lenguaje y la tecnología ?

El lenguaje: el más poderoso de todos los medios de acción del grupo sobre el individuo. El lenguaje, una técnica elaborada lentamente por la humanidad y que ha llegado a su estado actual, su estado perpetuamente cambiante e inestable tras no siglos sino milenios de trabajo. El lenguaje encargado, al final de este tiempo, con toda la serie de diferenciaciones, disociaciones, categorías que la humanidad logró crear poco a poco. Lenguaje cuya acción se une, por un lado, a la de los mitos que desempeñaron el papel de técnicas para la humanidad cuando ésta aún carecía del aparato capaz de darle el control sobre las cosas y, por otro lado, a la acción de las técnicas mismas, tan fuertemente relacionadas entre sí en una misma época, tan fuertemente participantes en un mismo estilo que puede ser fechado sin error. Todo esto, en una palabra, nos permite decir que el individuo es sólo lo que su época y su entorno social le permiten ser.

Pero entonces la alternativa : ¿individuos o masas? Si se prefiere, otro planteamiento del mismo problema : ¿individuos o sociedades? El medio social penetra desde luego en el autor de la obra histórica, lo enmarca y determina en gran medida en su creación. Y cuando esto se completa o muere, o bien, para vivir, debe recibir la colaboración activa, la temible colaboración de las masas, el peso del entorno, irresistible y constrictivo. En otros términos, la sociedad es para el hombre una necesidad, una realidad orgánica. Por sí mismo, tomando una expresión de H. Wallon, "el lenguaje implica la sociedad como los pulmones (d'une espèce aérienne) que implican la existencia de la atmósfera" Y de esta sociedad el individuo recibe sus determinaciones; son para él un complemento necesario ; "tiende hacia la vida social como hacia su estado de equilibrio".

\section{Desde el punto de vista de la psicología}

14 Ahora todo nos parece menos sencillo que al principio. Si, en cualquier individuo, cabe distinguir primero una persona determinada, más o menos claramente caracterizada, y luego un conjunto de rasgos que le pertenecen y cuya conjunción se hace según una fórmula y con una dosificación muy particular; si hay que recoger entonces en ese mismo individuo o bien un representante de la especie humana que lleva los mismos rasgos distintivos que los miembros de un cierto grupo de esa especie, o bien sobre todo un participante en una sociedad bien determinada y fechada : Por un lado, el contraste 
entre el individuo y la sociedad se atenúa tan singularmente que ya no hay lugar para oponer esquemáticamente el uno al otro ; por otro lado, el método de investigación comienza a definirse claramente.

Los tres deberes del psicólogo - Tres series de indagaciones, lo ocuparán a su turno. Debería empezar por entregarse a la investigación de lo que el hombre debe a su entorno social : la psicología colectiva. Podría, incluso, preguntarse qué debe el hombre a su organismo específico: la psicología específica o la psicofisiología. Por último, podría estudiar lo que tal ser humano debe a las particularidades individuales de su fisiología, a los incidentes de su estructura, a los accidentes, sobre todo, de su vida social : la psicología diferencial. En buena lógica, además, esta última debería intervenir sólo después de la profundización de las dos anteriores. Y mientras éstas no hayan progresado de forma decisiva, mientras los psicólogos no hayan conseguido sustituir a las especies psicológicas bien caracterizadas en el caos de los casos individuales, como en el caos de los síntomas los médicos sustituyen a las especies mórbidas ampliamente concebidas ; mientras no se hayan creado "tipos" que permitan, frente al individuo, la operación siempre delicada del diagnóstico que consiste en integrar el caso individual en cualquiera de las especies anteriormente creadas - la psicología diferencial debe resignarse a conservar algo empírico. Y esto, siendo verdadero en la psicología actual, lo es aún más en la psicología retrospectiva. Si quieres, en psicología histórica.

\subsection{El problema de la psicología histórica}

16 Porque, efectivamente, existe un problema especial en la psicología histórica. Cuando, en sus disertaciones, en sus tratados, los psicólogos nos hablan de las emociones, de las decisiones y del razonamiento del hombre, en realidad son nuestras emociones, nuestras decisiones y nuestro razonamiento de lo que están tratando. De nuestro lote, la de los hombres blancos de Europa Occidental, integrada, en este siglo XX, en grupos de cultura muy antigua. Ahora bien, ¿cómo podríamos ayudarnos los historiadores a interpretar los métodos de los hombres del pasado, gracias a una psicología resultante de la observación de los hombres del siglo XX ? ¿Y cómo podrían ellos, los psicólogos, encontrar, en los datos que la historia proporciona (o debería proporcionar) sobre la mentalidad de los hombres de antaño, un material con el que pudieran simplemente enriquecer una experiencia adquirida en contacto con sus contemporáneos? A lo sumo, esta experiencia podría proporcionarles el tipo de comparaciones que les permitiría comprender mejor las diferencias entre nuestros antepasados, directos o no, lejanos o cercanos a nosotros.

En realidad, ni la psicología de nuestros psicólogos contemporáneos es aplicable al pasado, ni la psicología de nuestros antepasados encuentra una posible aplicación a los hombres de hoy. Tanto si se trata de los héroes de la historia, de esos personajes históricos nuestros que nos son conocidos a través de un mayor o menor número de documentos biográficos y retratos físicos y mentales - como de las masas anónimas en las que no nos molestamos en analizar psicológicamente los elementos, ni en caracterizar globalmente las reacciones : en cualquiera de los dos casos "no se trataría, por utilizar los términos de Ch. Blondel (Introducción a la psicología colectiva, p. 197), de obstinarse en determinar de plano formas universales de sentir, pensar y actuar, tal vez inexistentes y en todo caso actualmente inaccesibles. Considerando aisladamente los grupos humanos diseminados en el espacio y en el tiempo, su papel es, por el contrario, 
describir los sistemas mentales propios de cada uno y analizarlos en la medida de lo posible, buscando percibir el mecanismo de su elaboración, el juego de su desarrollo y la naturaleza de las relaciones que vinculan sus elementos entre sí". No se puede decir mejor ni más claramente para denunciar el peligro : el de querer pasar directamente, y sin sospechar siquiera la dificultad, de los sentimientos e ideas que son nuestros a los sentimientos e ideas que las palabras similares, que las mismas palabras que generan las más graves confusiones, por su hipotética y falaz identidad, sirven siempre para identificar, a veces con algunos siglos de diferencia. ¿Necesitamos dos o tres ejemplos?

Algunos anacronismos psicológicos. - No los buscaremos demasiado lejos. Recordemos, como afirma Charles Blondel (obra citada, p. 202), que "si tomamos dos comunidades lo suficientemente alejadas una de otra en el tiempo o en el espacio, la diferencia de sus correspondientes mentalidades resaltará ante nuestros ojos"; mientras que, si están más cerca la una de la otra, se requerirán a veces largos y delicados esfuerzos e investigaciones para discernir las divergencias, que a menudo son considerables. No nos dirijamos, pues, ni a los pueblos primitivos de los que los notables estudios de Lucien Lévy-Bruhl tratan de analizar las formas de sentir, pensar y actuar (sus observaciones se adaptan esencialmente a la función, no de una historia, sino de una prehistoria, o, si se prefiere, de una paleontología psicológica), ni a los chinos cuyos ricos libros de Granet nos permiten comparar sus planteamientos intelectuales con los nuestros.

19 El apego a la vida - Formulemos simplemente una pregunta : ¿a qué se apega más el hombre de hoy, o si se quiere, a qué le cuesta más renunciar? Una pregunta que ya suscita reservas, porque: ¿hombre, qué hombre? - Pero estaremos de acuerdo en responder sin más reflexión : es a su vida. A su propia vida.

Sobre esto, abramos cualquiera de las obras de Frazer. Y en estos libros clásicos encontraremos puñados de hechos sorprendentes (al menos para nosotros) que nos mostrarán, entre sociedades relativamente cercanas a nosotros y a la nuestra, diferencias y contrastes realmente enormes en la apreciación de este valor que la propia "naturaleza" parecería promover para la primera de todas las posiciones. Allí aprenderíamos de la misma manera que pueblos enteros, durante siglos y siglos no han protegido sino destruido a sus propios hijos ofreciéndolos espontáneamente al sacrificio. Allí aprenderíamos que esta unión, para nosotros indisoluble, entre la divinidad y la inmortalidad, por no decir la eternidad, millones y millones de seres humanos la ignoraron y la siguen ignorando, creyeron, creen en la muerte de los dioses, crearon sus dioses mortales a su imagen. ¿Historias antiguas? Sin duda. Pero abramos el volumen $\mathrm{IX}$ de l'Histoire littéraire du sentiment religieux en France, del padre Henri Brémond. Se titula: La vie chrétienne sous l'ancien regime y contiene un sorprendente capítulo sobre el arte de morir. Muestra cómo hace menos de tres siglos los moribundos eran tratados con un tipo de crueldad (al menos en nuestra opinión) que nos aleja de nosotros mismos y de nuestra mentalidad.

21 La movilidad del humor en la edad media - Otros ejemplos. En las vidas novelizadas que en los últimos años hemos visto multiplicarse a placer -un placer quizás para los editores, pero no para el lector culto-, ¿qué es lo que choca al historiador y cómo se explica su mal humor ante este exceso biográfico? ¿Son los errores de hecho, a bien decir inevitables, el descuido, la confusión, la ineptitud reiterada de autores sin competencia ni preparación? ¿Serán los hábitos amargados del saqueo, el robo violento organizado o la ocultación cínica del autor en las obras de los verdaderos historiadores 
por parte de los apresurados panfletistas de la historiografía? ¡Y no! Es algo mucho más serio : el anacronismo, el perpetuo e irritante anacronismo de los hombres que se proyectan, tal como son, en el pasado, con sus sentimientos, sus ideas, sus prejuicios morales e intelectuales, y que, habiendo travestido a Ramsès II, Sesóstris, Julio Cesar, Carlos Magno o Felipe II o incluso Luis XIV en Dupont o Durand 1938 encuentran en sus héroes lo que acaban de atribuirles admirándose amablemente y concluyendo su "análisis" por este desconcertante nil novi: "Así es el hombre, siempre igual a sí mismo".

Ahora, sin ir más lejos, apelemos a nuestra experiencia como historiador. Es imposible estudiar la vida, las costumbres, los modos de ser y de actuar de los hombres de la Edad Media (una Edad Media que se extiende hasta el siglo XVI e incluso más allá), es imposible leer en los textos auténticos, relatos de príncipes, fiestas, procesiones, ejecuciones judiciales, sermones populares, etc., sin quedar impresionado por la asombrosa movilidad de los estados de ánimo, por la excesiva permeabilidad a las impresiones del exterior de la que hacen gala los hombres de aquella época. A punto de enfadarse, a punto de entusiasmarse, siempre a punto de desenvainar la espada pero no menos a punto de abrazarse. Se baila y se llora. Uno huele la sangre y luego las rosas. Hay que recordar, escribe el escritor holandés Huizinga en un libro muy sugerente (Le déclin du moyen-âge, 1932, p. 16), "hay que recordar esta receptividad, esta facilidad de emoción, esta propensión a las lágrimas, estos retornos espirituales, si se quiere concebir la aspereza del gusto, la violencia del color que tenía la vida en aquellos tiempos". Sin duda: pero es necesario sobre todo explicar. Y la explicación no es sencilla. Pone en juego una multitud de datos que los historiadores no se habían molestado hasta ahora en reunir, en agrupar en un cuerpo. A lo que no han pensado darle verdadero valor.

Condiciones de vida y mentalidad - ¿Hombres de grandes contrastes ? Pero su vida material -ya lo señalábamos hace quince años en una serie de artículos de la Revue des cours et conférences (1925)- ¿no estaba hecha ella misma de contrastes ? Pensemos en cosas muy simples, muy pesadas, de las que nunca medimos el peso.

Día-noche - ¿Qué es para nosotros, hombres del siglo XX, el contraste entre el día y la noche ? En general, nada. Un botón, un gesto y la luz eléctrica sustituye a la luz solar. Maestros del día y de la noche lo hacemos con virtuosismo. ¿Y los hombres de la Edad Media? ¿Y los del siglo XVI ? No dominaban eso, los pobres, que ni siquiera tenían lámparas de aceite cuando caía la noche ni siquiera velas. Una vida numerada, ritmada cada día por la sucesión de la oscuridad y de la luz ; una vida truncada en dos partes, la noche y el día; el blanco y el negro; el silencio absoluto y el ruido del trabajo ¿podemos creer que haya podido engendrar en los hombres los mismos hábitos mentales, las mismas formas de pensar, de sentir, de querer, de actuar y de reaccionar que nuestra vida estabilizada, regularizada, desprovista de choques, de contrastes y de enfrentamientos brutales?

Invierno-verano - día y noche - pero ¿invierno y verano ? ¿Se refiere a frío y calor ? ¿Todavía hay invierno para nosotros? Cuando queramos : pero siempre acompañado de un verano que sólo depende de nosotros. Todo el día esquiando en la nieve. Pero por la noche en el hotel calentado a 20 grados. Calentado por todas partes. Cuando entras en una casa hoy, en pleno invierno, ¿no sientes el cálido aliento de los radiadores en tu cara ? Te desnudas. Pero cuando entrabas en una casa del siglo XVI, en enero, sentías el frío caer sobre tus hombros: el frío quieto, silencioso y negro de los alojamientos sin 
calefacción. Ya estabas temblando de antemano. Así como temblaste en la iglesia. Como en el palacio del rey, a pesar de las enormes chimeneas que consumían árboles enteros. Y el primer gesto del hombre que volvía (a casa) no era quitarse el abrigo, sino ponerse un abrigo más cálido que el que había dejado. Y se ponía en la cabeza un gorro con un forro más grueso que el de la calle. Invierno - verano : dulces contrastes para el más humilde de los hombres de nuestro tiempo. Contrastes de violencia salvaje para los más pomposos, los más ricos de los hombres que los de antaño. Y sin duda -pero esto lo tienen que decir los psicólogos- la igualación de las condiciones de la vida material, la igualación de los hombres : ¿no se suceden ambas cosas, no se arrastran lógicamente, no se condicionan en absoluto?

Fortunio - la desgracia - ¿Y las condiciones de seguridad? Seguridad en las casualidades: ¿un incendio en el momento actual, un accidente, una muerte prematura? Los actos de los seguros. ¿en otro tiempo ? Tengamos en cuenta que no se trata de casos individuales. Cuando el fuego comenzaba de una de las extremidades de una ciudad llegando a las casas cubiertas de tablones de madera, impulsado por un viento violento, consumía por completo este barrio, arrasando en pocos minutos un pueblo entero, sorprendido durante la noche, sin medios de defensa, sin poder salvar ni siquiera a sus animales - había diez, veinte, cien familias que veían de repente sus vínculos desgarrados : los niños eran abandonados en los caminos, perdidos de vista, sin saber ya dónde encontrar a sus hermanos y hermanas. La seguridad de la vida, nada menos : no la desarrollemos.

El capítulo de la alimentación - ¿Y el inmenso capítulo de la alimentación, sus condiciones y sus influencias? La psicología de las poblaciones sobrealimentadas, en períodos de prosperidad y disponiendo de alimentos ricos y variados en abundancia, es la de, puede ser la de las poblaciones perpetuamente desnutridas construyendo un régimen de vida precario al margen de la inanición y pereciendo en masa como esos esquimales de los que se habla en otro volumen de la Encyclopédie, Lucie Randouin¿Desde cuándo, por la filantropía de los europeos compasivos, introducen en su dieta alimentos más ricos que rompen el precario equilibrio de su ración al que los pioneros de la nueva ciencia de la alimentación dan tanta importancia?

El testimonio de John Bull - ¿Es necesario recordar que la Edad Media fue una época de desnutrición permanente, de penurias y hambrunas suspendidas en ciertos días por una alimentación anormal ? ¿Y necesita este régimen admitir que engendró, que preservó hombres del mismo contexto físico y mental que nuestros propios regímenes nuestros regímenes de gordos sedentarios, sucediendo el martirio del hombre hambriento con el martirio del hombre obeso? Pensemos simplemente en la brutal sucesión de estas imágenes de pueblos, registradas en la retina de sus propios vecinos; pensemos en la población de ranas escuálidas, blancas y hambrientas, que los ingleses del siglo XVIII imaginaron, y no era sin razón que lo imaginaran, viviendo en las orillas del Sena mientras ellos mismos se reconocían en John Bull, el apopléjico - alimentado copiosamente con carnes rojas y sangrientas regadas con el alcohol de las cervezas: tantas sugerencias y peticiones de estudios que no se hacen y que sería necesario hacer.

\section{Conclusión : colaboración necesaria}

29 No sigamos. Hemos dicho lo suficiente para demostrar que si nos impedimos proyectar el presente, nuestro presente, en el pasado, que es la ley fundamental de la historia, si 
nos negamos al anacronismo psicológico, el peor de todos, el más insidioso y el más grave, si pretendemos esclarecer todos los procesos de la sociedad y en primer lugar los mentales mediante el examen de sus condiciones generales de existencia, es evidente que no podremos tomar como válidos, en el pasado que así trataremos de inventariar, las descripciones y los hallazgos de nuestros psicólogos, operando con los datos que nuestra época les suministra. Y no es menos evidente que una verdadera psicología histórica sólo será posible mediante un entendimiento, claramente negociado, entre el psicólogo y el historiador. Esta última guiada por aquel. Pero el primero, estrechamente dependiente del segundo y obligado a asumir la tarea de crear las condiciones de su trabajo. Trabajo en colaboración. Trabajo en equipo, para decirlo más claramente.

La tarea del mañana - Y, en efecto, inventariar, primero en detalle y luego reconstruir, para el período estudiado, el material mental de que disponían los hombres de esa época; mediante un poderoso esfuerzo de erudición pero también de imaginación, reconstituir el universo, todo el universo físico, intelectual y moral en el que se movía cada una de las generaciones que la precedieron; adquirir un pensamiento claro y cierto de que, por un lado, la insuficiencia de nociones fácticas sobre tal o cual tema, por otro, la naturaleza del material técnico en uso por la sociedad de la época que se intenta estudiar, engendraría necesariamente lagunas y deformaciones en las representaciones que esa colectividad histórica interiorizó del mundo, de la vida, de la religión, de la política; para darse cuenta finalmente, tomando prestada la frase de Wallon, "de que el universo en el que sólo la fuerza muscular del hombre está a disposición de los seres concretos que están ante él", no es ni puede ser el mismo universo en el que el hombre ha sometido la electricidad a sus necesidades y puede producir esa electricidad sometiendo a las propias fuerzas de la naturaleza; Comprender, en una palabra, que el universo no es más un absoluto que el "espíritu" o que el "individuo", sino que se transforma incesantemente con las invenciones, con las civilizaciones que engendran las sociedades humanas, éste es el siguiente ideal, la meta que constituye el fin último del historiador; pero esta meta no la alcanzarán los historiadores aislados. Incluso si se preocupan por vincularse con los psicólogos.

31 Su enormidad y sus condiciones - La tarea es tan enorme que requiere proporcionar a los psicólogos los materiales que necesitan para elaborar una psicología histórica válida. Es tan enorme que no sólo está más allá de la fuerza y los medios de un solo hombre : está más allá del dominio de una ciencia o incluso de dos. Supone, para que se lleve bien a cabo, la negociación de toda una red de alianzas. ¿Estamos hablando de técnicas? En el caso de las sociedades civilizadas del pasado, la ayuda efectiva de una arqueología que arroja sus presas sobre tiempos mucho más cercanos a nosotros que la propia antigüedad. Es necesario, tratándose de las sociedades actuales, la ayuda no menos eficaz de una etnología que no limita en absoluto sus esfuerzos de inventario a los primitivos y trata, como los Lacandones de Soustelle o los tupí-guaraní de Métreaux, poblaciones mucho más cercanas a nosotros y mucho más ricas en recursos de civilización. Igualmente, si se trata de la lengua, esa otra vía cardinal de acceso a lo social en el individuo : es necesaria la colaboración de los filólogos levantando esos inventarios de lenguas que no están hechos para los historiadores pero de los que pueden sacar tanto provecho: no los inventarios globales de esas grandes lenguas civilizatorias que funden las aportaciones de tantos grupos locales o sociales diferentes y nos las entregan en bruto, sino esos inventarios de patois que interpretados por el historiador de las sociedades rurales proporcionan tantas lecciones preciosas que sólo 
ellos pueden aportar. Pero no es menos necesaria la colaboración de los semánticos que, al devolvernos la historia de las palabras particularmente cargadas de significado, escriben con precisión, de la misma pluma, capítulos de la historia de las ideas. Es necesaria la colaboración de aquellos historiadores de las lenguas, como Meillet escribiendo la historia de la lengua griega o como Ferdinand Brunot siguiendo paso a paso los destinos de la lengua francesa que se refieren a la aparición, en determinadas fechas, de todo un contingente de palabras nuevas o de nuevos significados dados a palabras antiguas. Es necesaria, para pasar de un juego de signos a otro, la colaboración de esos exégetas de la iconografía que, con monumentos fechados, restauran la historia de sentimentalismos religiosos muy complejos. Es necesario... no sigamos con la enumeración porque todo se puede resumir también, en una palabra: se necesitan espíritus despiertos, inventivos, ingeniosos, que busquen colaboraciones y que, ante cualquier trabajo intelectual, se hagan la pregunta del investigador: ¿para qué me puede servir esto ? ¿Y cómo puedo utilizar lo que no está hecho para mí?

Y, por tanto, al trabajo. El problema no es el de la teoría. No es la de si cualquier historia (política, social, económica, intelectual) de los grupos humanos debe ordenarse en función de un "psicológico en primer lugar", en torno a una historia del pensamiento, del sentimiento y de la voluntad recogida en transformaciones cronológicas. Fue una idea aún reciente de Karl Lamprecht. Discutiremos por otra parte, estas grandes tesis doctrinales; no se tratarán aquí. Aquí se trata simplemente de apelar con nuestros deseos a la búsqueda de un trabajo positivo urgente del que acabamos de registrar las condiciones inmediatas. Aquí se trata de integrar una psicología histórica totalmente nueva, por crear, en la poderosa corriente de una historia que la dirige como todo hacia el destino de la humanidad, de una humanidad que marcha sin saber hacia dónde se dirige. 